\title{
THE EFFECT OF MULTI LAYER SWITCH FOR SPEED DATA TRANSFER ON COMPUTER NETWORK
}

\author{
Sudaryanto \\ Departemen Informatika \\ Sekolah Tinggi Teknologi Adisutjipto Yogyakarta \\ J1. Janti, Blok R, Lanud Adisutjipto Yogyakarta \\ sudaryanto@stta.ac.id
}

\begin{abstract}
The need for efficient, stable, fast and reliable network access is influenced by network quality, one of the factors influencing network quality is the management of network devices, while the network devices that are enforced are the Lancard, cable, Switch, Router, Wifi Access Point and Compuitary System. In this study researchers will focus on the influence of Multilayer Switch network devices for data transfer speeds on computer networks. Data transfer speed at layer 2 text data, image data, video data faster 0,85\% than for speed tranfers on layer 3 text data, image data, video data.
\end{abstract}

Keyword: Network, Switch Multilayer, Data Tranfer, Osi Layer

\section{Latar Belakang}

Teknologi dalam jaringan komputer lambat laun semakin pesat seiring dengan meningkatnya kebutuhan akan akses jaringan yang efisien, stabil dan cepat serta kemanan yang handal, sehingga jaringan komputer dianggap sebagai backbone dari teknologi informasi dan diharapkan dapat menyediakan layanan yang aman bagi penggunanya, sehingga informasi-informasi atau data penting dapat dikirim dan diterima dengan baik dan cepat.

Perangkat Jaringan Switch Multilayer adalah teknologi terbaru dari CISCO yang dipergunakan salah satunya untuk melengkapi perangkat jaringan yang mempunyai tuntutan kemajuan teknologi. Pada penelitian ini akan membahas pengaruh switch multilayer untuk kecepatan transfer pada jaringan komputer.

\section{Metodologi Penelitian}

\subsection{Jaringan Komputer}

Jaringan komputer adalah sebuah kumpulan perangkat komputer, switch, router, printer dan peralatan lainnya yang dapat terhubung dalam satu kesatuan [1]. Data dan informasi bergerak melalui kabel-kabel UTP sehingga memungkinkan pengguna perangkat jaringan dapat saling bertukar dokumen dan data, mencetak pada printer yang sama dan bersama-sama menggunakan hardware/software yang terhubung dengan jaringan. Tiap komputer atau periferal yang terhubung dengan jaringan disebut node. Sebuah jaringan komputer dapat memiliki dua, puluhan, ratusan, ribuan atau bahkan jutaan node.

Sebuah jaringan biasanya terdiri dari 2 atau lebih komputer yang saling berhubungan diantara satu dengan yang lain, dan saling berbagi sumber daya misalnya pertukaran file, melakukan pencetakan pada printer atau memungkinkan untuk saling berkomunikasi secara elektronik.

\subsection{Switch Unmanageable}

Switch merupakan sebuah perangkat yang mempunyai fungsi untuk menghubungkan beberapa komputer ataupun perangkat jaringan agar dapat berbagi sumber daya [2]. Switch bisa diartikan juga sebuah perangkat keras yang digunakan untuk mendistribusi packet data antara komputer ataupun beberapa perangkat jaringan dalam sebuah jaringan dan mampu untuk mengenali topologi jaringan dengan layer yang banyak sehingga data dapat langsung sampai ketujuan, switch juga mempunyai memori yang disebut dengan Content Addressable Memory (CAM) atau dikenal 
juga dengan sebutan MAC address table, setiap perangkat yang terhubung ke switch maka secara otomatis seluruh MAC address setiap perangkat yang terhubung dengannya akan disimpan kedalam MAC address table.

Pada Gambar 1 dapat dilihat bahwa perangkat switch tersebut mempunyai 24 port, namun jenis swich ini tidak mendukung kemampuan untuk kualitas layanan yang handal dijaringan maupan keamanan. Jenis Switch ini adalah jenis switch yang tidak bisa dikonfigurasi atau unmanageable.

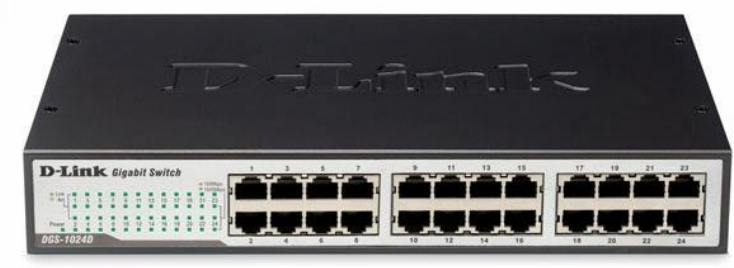

Gambar 1. Switch unmanageable

\subsection{Switch Manageable}

Pada switch Manageable ditunjukan Gambar 2 mempunyai fungsi yang sama dengan switch unmanageable namun banyak fitur-fitur tambahan yang dapat membedakan switch unmanageable yaitu dengan meningkatkan kualitas dari jaringan tersebut,

\subsubsection{Switch Non Multilayer}

Jenis switch yang hanya bekerja di layer data link, fitur yang paling sering digunakan adalah kemampuan switch dalam konfigurasi Virtual LAN (VLAN) dan traffic jaringan yang bisa dikontrol/diatur.

\subsubsection{Switch Multilayer}

Jenis switch yang mampu bekerja di layer data link dan layer Network. Pada layer data link kemampuan switch sama dengan Switch Non Multilayer sedangkan pada layer Network bisa di konfigurasi sesuai dengan keinginan administrator dan juga dapat dilakukan proses routing ataupun menghubungkan alamat network yang berbeda. Perubahan penggunaan layer ditandai dengan perintah \#no switchport, contoh Script:

Switch\#configure terminal

Switch(config)\#interface FastEthernet 0/1

Switch(config-if)\#no switchport

Switch(config-if)\#ip address 192.130.10.1 255.255.255.0

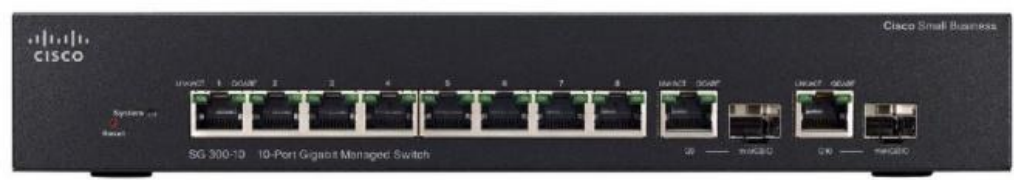

Gambar 2. Switch manageable

\subsection{Kebutuhan Sistem}

Dalam melakukan penelitian ini, penulis melakukan proses perancangan sistem. Hal ini dimaksudkan untuk mempermudah proses pengambilan data penelitian menjadi lebih terstruktur. Perancangan sistem dimulai dengan analisis kebutuhan perangkat lunak maupun perangkat keras, dan deskripsi perangkat lunak. 


\subsubsection{Kebutuhan Hardware}

Perangkat keras dibutuhkan agar dengan efesien dapat menjalankan perangkat lunak dengan baik. Perangkat keras yang digunakan untuk pengambilan data yaitu:

1. Switch Multiulayer Catalyst 3750 Series

2. Switch Non Multilayer Catalyst 2950 Series

\subsubsection{Kebutuhan Software}

Perangkat Lunak (software) merupakan salah satu komponen penting untuk membantu pengambilan data. Jenis-jenis software atau perangkat lunak yang dibutuhkan untuk membantu proses pengambilan data adalah:

1. Linux 14.08 untuk server

2. Windows 10 untuk client

3. Sistem Operasi Cisco yang tertanam pada Switch

\subsection{Skema Dasar Jaringan}

Skema dasar jaringan yang akan dibangun untuk mendukung pangambilan data dapat dilihat pada Gambar 3 dan Gambar 4, skema jaringan hanya berbasis local area network.

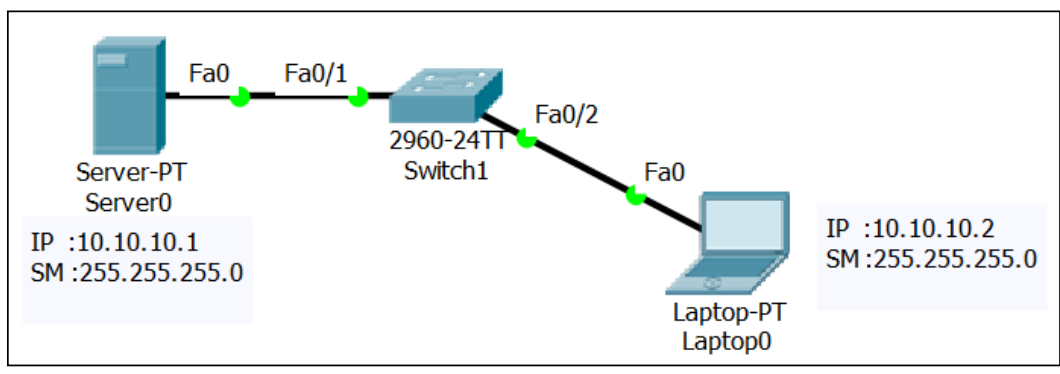

Gambar 3. Skema pengambilan data dengan Switch Non Multilayer layer data link

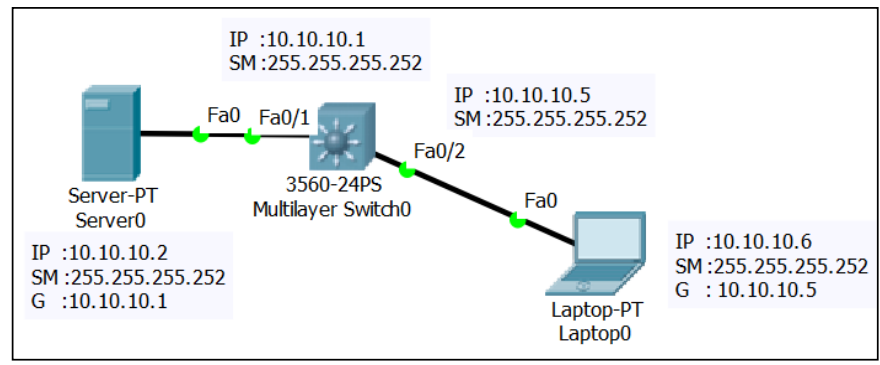

Gambar 4. Skema pengambilan data dengan Switch Multilayer layer Network

\section{Hasil dan Pembahasan}

Tampilan dari antarmuka client untuk proses pengiriman data ke server dengan menyediakan 1 komputer sebagai server dan 1 buah komputer sebagai Client beserta dengan pengukuran waktu transfer data (Inspect Element $(Q)$ pada browser Mozila) ditunjukan pada Gambar 5. Pengujian dilakukan terhadap 30 (tiga puluh) buah data yang terdiri dari 10 (sepuluh) data text, 10 (sepuluh) data image dan 10 (sepuluih) data video dengan format *.MP4 masing-masing dengan ukuran file yang berbeda-beda. Waktu proses transfer data yang akan diamati oleh peneliti. 


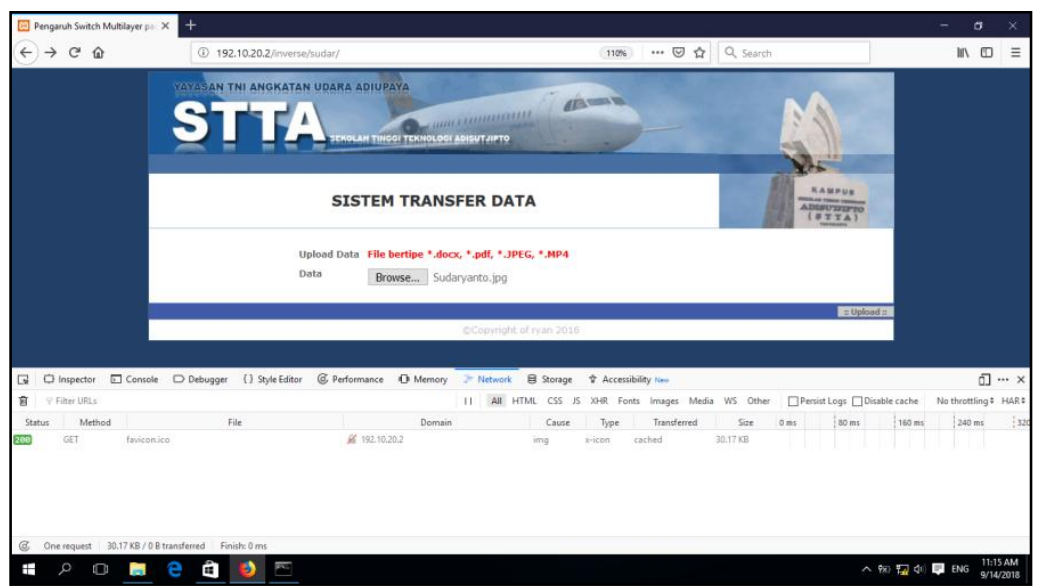

Gambar 5. Tampilan Antarmuka Client

Pengujian data uji akan dilakukan sebanyak 2 tahap, tahap yang pertama akan dilakukan transfer data dengan Swicth Non Multilayer melalui layer 2 data link Gambar 6. Ditahap ini akan dibagi menjadi 3 (tiga tahap) tahap yang pertama adalah akan mengirimkan data text ke server, tahap kedua akan mengirimkan data image ke server dan tahap ke tiga akan mengirimkan data video ke server. Pada tahap kedua dilakukan sama dengan tahap pertama tetapi dengan menggunakan Switch Multilayer melalui layer 3 network dapat dilihat pada Gambar 7. Pengujian ini dilakukan pada masing-masing tahap dengan data sebanyak 10 (sepuluh) data yang bervariasi dari segi ukuran file dan ukuran frame dan satu data akan dikirimkan 3 (tiga) kali Pada tiap tahap pengujian akan dilakukan pendataan terhadap ukuran data hasil yang dikirimkan dan waktu proses pengiriman data.

Setelah dilakukan uji coba tahap pertama, aplikasi berhasil melakukan proses pengiriman data pada ke-30 data uji sehingga menghasilkan output data dengan ukuran file yang sama dibanding dengan ukuran file asli. Dan berdasarkan uji coba, pengukuran waktu proses transfer data terhadap kes-30 data uji dengan menggunakan Inspect Element $(Q)$ pada browser Mozila Firefox dapat dilihat pada Tabel 1 yang menjelaskan tentang data parameter transfer data pada aplikasi transfer data menggunakan data text (nomor 1-10), image (nomor 11-20) dan video (nomor 21-30).

Tabel 1. Tabel hasil pengujian Switch Non Multilayer dan Switch Multilayer

\begin{tabular}{|c|c|c|c|c|c|c|}
\hline \multirow[b]{2}{*}{$\mathrm{NO}$} & \multirow[b]{2}{*}{ Nama File } & \multirow[b]{2}{*}{$\begin{array}{c}\text { Jenis } \\
\text { File }\end{array}$} & \multicolumn{2}{|c|}{ Size } & \multicolumn{2}{|c|}{ Waktu (Second) } \\
\hline & & & $\begin{array}{l}\text { Sebelum } \\
(\mathrm{KB})\end{array}$ & $\begin{array}{l}\text { Sesudah } \\
(\mathrm{KB})\end{array}$ & $\begin{array}{l}\text { Switch Non } \\
\text { Multilayer }\end{array}$ & $\begin{array}{c}\text { Switch } \\
\text { Multilayer }\end{array}$ \\
\hline 1 & Administrasi & *.ppt & 5,456 & 5,456 & 484.67 & 500 \\
\hline 2 & Laporan P3M & $*$ doc & 8,383 & 8,383 & 748.67 & 744.67 \\
\hline 3 & $\begin{array}{l}\text { Modul } \\
\text { Pengabdian }\end{array}$ & $*$. doc & 12,902 & 12,902 & $1,125.67$ & $1,140.67$ \\
\hline 4 & $\begin{array}{l}\text { Proposal } \\
\text { Pengabdian }\end{array}$ & *.pdf & 1,117 & 1,117 & 135.00 & 131.33 \\
\hline 5 & Bukti publikasi & $*$.doc & 4,515 & 4,515 & 412.33 & 417.00 \\
\hline 6 & Naskah Ujian & *.docx & 145 & 145 & 173.00 & 255.67 \\
\hline 7 & Skep Pengabdian & $* . p d f$ & 3,033 & 3,033 & 281.33 & 287.33 \\
\hline 8 & Poster & *.cdr & 6,401 & 6,401 & 569.33 & 660.33 \\
\hline 9 & Prosiding & *.pdf & 22,671 & 22,671 & $1,984.67$ & $1,979.33$ \\
\hline 10 & Web Server & *.ppt & 2,775 & 2,775 & 255.00 & 255.33 \\
\hline 11 & Cetak1 & *.jpg & 1,159 & 1,159 & 119.67 & 120 \\
\hline 12 & Cetak2 & *.jpg & 985 & 985 & 113 & 116 \\
\hline 13 & Cetak3 & *.jpg & 2,403 & 2,403 & 226.67 & 239.67 \\
\hline 14 & Cetak4 & *.jpg & 1,841 & 1,841 & 181 & 184.67 \\
\hline 15 & Cetak5 & $* . j p g$ & 5,977 & 5,977 & 533 & 550 \\
\hline
\end{tabular}




\begin{tabular}{|l|l|l|r|r|r|r|}
\hline 16 & Cetak6 & $* . j p g$ & 3,080 & 3,080 & 285.67 & 290.33 \\
\hline 17 & Cetak7 & $* . j p g$ & 4,482 & 4,482 & 393 & 410.33 \\
\hline 18 & Cetak8 & $* . j p g$ & 4,970 & 4,970 & 447.33 & 452.67 \\
\hline 19 & Cetak9 & $* . j p g$ & 7,8138 & 7,8138 & 753 & 748 \\
\hline 20 & Cetak10 & $* . j p g$ & 10,51 & 10,51 & 953.33 & 948 \\
\hline 21 & Abby's Gala & $* . M P 4$ & 4,947 & 4,947 & 459.67 & 474.67 \\
\hline 22 & Cristina Perri & $* . M P 4$ & 62,090 & 62,090 & 5388 & $5,401.33$ \\
\hline 23 & Lagu Hari & $* . M P 4$ & 15,954 & 15,954 & 1402 & $1,457.67$ \\
& Pertama & & & & 2090 & $2,091.00$ \\
\hline 24 & Six Little Ducks & $* . M P 4$ & 23,492 & 23,492 & 4131.33 & $4,172.67$ \\
\hline 25 & Sweet Child'O & $* . M P 4$ & 47,403 & 47,403 & 3690.67 & $36,908.00$ \\
\hline 26 & Video 1 & $* . M P 4$ & 411,320 & 411,320 & 36940 & $2,983.33$ \\
\hline 27 & Video 2 & $* . M P 4$ & 34,807 & 34,807 & 2944 & $16,763.00$ \\
\hline 28 & Video 3 & $* . M P 4$ & 187,026 & 187,026 & 16718.33 & $63,555.33$ \\
\hline 29 & Video 4 & $* . M P 4$ & 692,047 & 692,047 & 62812.67 & 637 \\
\hline 30 & Whells On The & $* . M P 4$ & 10,517 & 10,517 & 943.33 & 956.00 \\
& Bus & & & & & \\
\hline
\end{tabular}

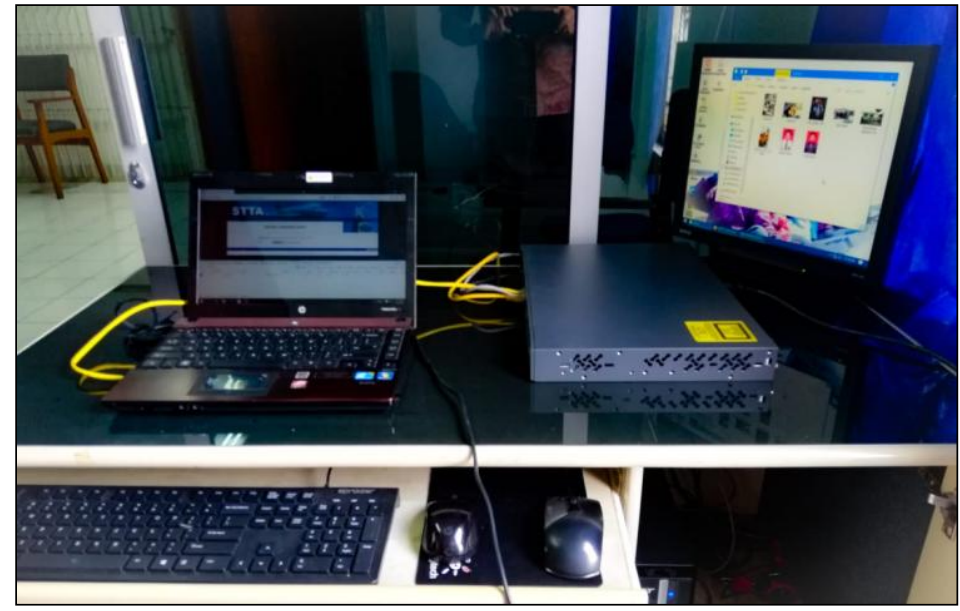

Gambar 6. Foto Pengujian Switch

Dari hasil pengujian dilihat pada Tabel 1 dapat dihitung untuk perbandingan kecepatan

Percepatan $\%=\frac{(\text { Nilai Percepatan })}{\text { Nilai Sebelum Percepatan }} \times 100 \%$

$$
\text { Percepatan data Text } \%=\frac{(637.17-619.97)}{619.97} \times 100 \%
$$

\section{Percepatan data Text $\%=3,27 \%$}

Dari hasil pengujian perhitungan percepatan transfer data Text kecepatan transfer data Text dengan menggunakan Switch Non Multilayer lebih cepat 3,27\% daripada Switch Multilayer sedangkan pengujian perhitungan percepatan transfer data Image kecepatan transfer data Image dengan menggunakan Switch Non Multilayer lebih cepat 1,85\% daripada Switch Multilayer dan hasil pengujian perhitungan percepatan transfer data Video, kecepatan transfer data Video dengan menggunakan Switch Non Multilayer lebih cepat 0,697\% daripada Switch Multilayer.

Dari perhitungan percepatan baik data Text, Image dan Video dapat disimpulkan bahwa kecepatan transfer data dengan menggunakan Switch Non Multilayer lebih cepat 0,85\% daripada Switch Multilayer. Maka dengan adanya penelitian ini dapat diketahui dari sisi kecepatan transfer 
data dengan menggunakan Switch Non Multilayer dan Switch Multilayer tidak terlalu signifikan tetapi untuk implementasi dalam sebuah jaringan dengan alamat network yang berbeda dengan menggunakan Switch Multilayer koneksi jaringan akan tersambung tanpa menggunakan router. Sedangkan Switch Non Multilayer tidak ada fasilitas routing.

\section{Kesimpulan}

Berdasarkan hasil dari penelitian dengan judul "Pengaruh Switch Multilayer untuk keceptatan transfer pada jaringan komputer" maka dapat diambil beberapa kesimpulkan sebagai berikut:

1. Kecepatan transfer data dengan menggunakan Switch Non Multilayer lebih cepat $0,85 \%$ dibandingkan dengan Switch Multilayer.

2. Kelebihan Switch Multilayer adalah dapat berjalan di 2 layer yang berbeda yaitu layer data link dan layer network.

\section{Daftar Pustaka}

[1] Kusumaningrum, A. (2016, November). Pengujian Kinerja Jaringan Sistem Akses File Berbasis Client Server Menggunakan Samba Server. In Conference SENATIK STT Adisutjipto Yogyakarta (Vol. 2, pp. 129-134).

[2] Sulaiman, K. (2016). Analisis Sistem Keamanan Jaringan Dengan Menggunakan Switch Port Security. CESS (Journal Of Computer Engineering, System And Science) (Vol. 1, ISSN :2502-7131)

[3] Marin, G.A. (2015, November). Network Security Basics, Security \& Privacy. IEEE. (Vol. 3, No 6 pp. 68-72).

[4] Saleh, I., Wintolo, H., \& Nugraheni, D. (2014, November). Analisa Perbandingan Waktu Dan Kecepatan Transfer Pada Multi Protocol Label Switching (Mpls) Dengan Virtual Private Network (Vpn) Untuk Perpindahan Dokumen Pada Jaringankomputer. In Compiler STT Adisutjipto Yogyakarta (Vol. 3, pp. 101-111).

[5] Pratama, A.W., Wintolo H., \& Astuti, Y. (2013). Konfigurasi Inter-Vlan Pada Cisco Berbasis Graphics User Interface (GUI) Sebagai Pembelajaran Peralatan Jaringan Komputer Cisco. In Compiler STT Adisutjipto Yogyakarta (Vol. 2, pp. 13-19).

[6] Sofana, I. (2010). Cisco CCNA \& Jaringan Komputer. Bandung. Informatika Bandung.

[7] Sutanto, F. A., Yulianton, H., \& Razaq, J. A. (2011). Rancang Bangun VLAN Untuk Segmentasi Jaringan Pada Cyber Campus Laboratory Universitas STIKUBANK. Dinamik, $16(2)$. 